\title{
Epidemiological Profile of the Head- Neck Pathologies in Referral Institute
}

\author{
Sabyasachi Ghosh, ${ }^{1}$ Tarak Nath Saha, ${ }^{1}$ Indranil Sen ${ }^{1}$
}

\section{Introduction:}

\section{ABSTRACT}

Head and neck lesions encompass a multitude of disorders which can be broadly classified into two groups: Benign and Malignant. Overall 57.5\% of global head and neck cancers comes from Asia itself and India alone constitutes $30 \%$ of it. Therefore, it is of prime essence that need based and coordinated research for understanding the threats to the nation from chronic diseases such as head and neck cancers and ways to defy such threats should gain the utmost importance. The present study attempts to present the epidemiological profile of the patients attending a peripheral referral institute of this state with head-neck pathologies and has undergone a histopathological examination of their lesions within a period of three years period (2016-18) based on the histopathological evidences.

\section{Materials and Methods:}

The accumulated data regarding the aforesaid patients as per records of the histopathological reports available in the Department of Pathology was used as the primary material and the interrelation of different epidemiological parameters were studied using the statistical methods

\section{Results:}

Six hundred and eighty seven cases from the head and neck region were analysed during this three-year period. Age range was from 3 years to 96 years with maximum cases in the age group of 20-29 years (16.1\%). The Male: Female ratio in our study was 1.34:1 (Males 394, Females 293). In this study, 38.8\% benign, 32.46\% malignant, 25.32\% inflammatory and 3.3\% congenital cases were recorded. Maximum number of benign lesions was in the age group of 10-39 years. Malignancies were noted to be higher in ages 40 years and above. Squamous cell carcinoma was the most common malignancy observed.

\section{Conclusion:}

Specific data obtained like this from histopathological records is helpful in evaluating patterns of head and neck lesions and augment the base line data of institute and the region.

Kevwords:

Head and Neck; Chronic Disease

$\mathrm{H}$ ead and neck lesions are commonly encountered in patients across all age groups. ${ }^{1}$ This region encompass a multitude of congenital, inflammatory or neoplastic lesions. These pathological lesions arise at several anatomical sites in the head and neck region and originate from different organs and tissues with varying histology and biological behaviour. ${ }^{2,3}$ Various anatomic sites include oral, upper aero-digestive

1 - Midnapore Medical College, Midnapore

\section{Corresponding author:}

Dr Tarak Nath Saha

email: drtaraknathsaha@gmail.com tract, otic, thyroid, salivary glands, lymph nodes, skin and soft tissues. ${ }^{4,5}$ Common benign and inflammatory lesions of head and neck region include various cysts and swellings of skin and subcutaneous tissues, Koch's and other inflammations, goiter, salivary gland swellings, lymphadenitis and oral lesions. ${ }^{5,6}$ Malignancies in head and neck region are the tenth most common cancers in the world and are an important cause of morbidity and mortality in affected patients. ${ }^{3,7}$ Malignant lesions can present as primary as well as secondary lesions from other organs.

A major chunk of head and neck lesions constitute malignancies of head and neck. Head and neck cancer is 
a collective term based on anatomical and topographic definitions for describing malignant tumors of the upper aerodigestive tract. This anatomical region comprises the oral cavity, the pharynx and the larynx. "Oral cancer" is one of the major subgroups of head and neck carcinomas; it involves the mucosa of the mouth (lips, base of tongue, tongue, floor of the mouth and the hard palate) and pharynx (oropharynx, hypopharynx and nasopharynx). About $40 \%$ of head and neck cancers occur in the oral cavity, $15 \%$ occur in the pharynx, $25 \%$ occur in the larynx and the remaining tumors occur in other sites (salivary glands and thyroid). The most frequent histological type, occurring in over $90 \%$ of cases, is the squamous cell carcinoma. ${ }^{8}$

The variation in incidence and prevalence of OSCC (oral squamous cell carcinoma) is predominately attributed to demographic differences in the habits of tobacco use and alcohol consumption which contributes to the development of almost $80 \%$ of all HNSCC diagnosed globally. In high-risk countries (i.e. India, Sri Lanka, Bangladesh and Pakistan), OSCC is the most common cancer in men and the third most common cancer in women. ${ }^{9}$

The present study is aimed to review the histological patterns of biopsied head and neck lesions as information regarding the types and the frequencies of head and neck lesions is helpful in management of the patients. Only a few studies have been reported so far focusing overall histopathological spectrum including inflammatory, congenital, benign and malignant lesions of this region.

\section{Materials and Methods}

The study was conducted in the Departments of Otorhinolaryngology and Pathology in a Peripheral Referral Institute, West Bengal, after obtaining due permission from the Institutional Authority as well as IEC. The study consisted of retrospective analysis of three years, from 1st January 2016 to 31 st October 2018. All histopathological data, pertaining to head and neck lesions, maintained in the histopathology section of the department of pathology were retrieved and reviewed. Haematoxylin and Eosin (H\&E) stained microscopic sections were re-examined. New H\&E stained paraffin sections were made wherever required such as in case of faded slides. All relevant clinical details were obtained from the available records. Records of all lesions involving oral cavity, upper aero digestive tract (nasal, paranasal sinus, oropharynx, nasopharynx, larynx and upper esophagus), aural region, salivary gland, lymph node, thyroid and skin and soft tissues were included. Intra orbital and intracranial biopsies were excluded from the study.

\section{Results}

A total of 687 cases from the head and neck region were analysed per age, gender, topography and histology. The patient's ages ranged from 3 years to 96 years. More than half of the lesions $(62.1 \%)$ were noted in the age group of $20-59$ years. $19.1 \%$ cases were noted in pediatric and adolescent age group and age group 60 and above was $18.3 \%$ (Table 1$)$. There were $394(57.3 \%)$ males and 293 (42.7\%) females. The Male: Female ratio was 1.34:1 (Table I).

The topographical distribution showed that oral cavity lesions were the most frequent, accounting for $33.3 \%$ cases followed by lesions externally over nose and paranasal sinuses which constituted $15 \%$ of cases. Lesions comprising of soft tissues over neck including the cervical lymph nodes constitutes about $8 \%$ of the total patients encountered. Pathologies relating to face were quite significant in number, amounting to $9.3 \%$. The burden of laryngeal malignant lesions was also in high numbers accounting to $8 \%$.Thyroid lesions accounted for $8.8 \%$ cases. Less common sites included parathyroid $(0.1 \%)$, nasopharynx $(1.6 \%)$, and ophthalmologic (1.4\%) (Table II).

The lesions were histologically categorized into benign, inflammatory, malignant and congenital. Out of the total 687 patients, $38.8 \%$ were benign, $25.32 \%$ were inflammatory, $32.46 \%$ were malignant and $3.3 \%$ were congenital (Table III). The malignant segment showed a male preponderance of about $83.4 \%$ of overall malignant cases. While females had a major impact over the benign and inflammatory segments comprising of about $56.9 \%$ and $53.4 \%$ respectively. The congenital cases had an almost equal gender prevalence. (Table 
Table I: Basic demographics of the study population concerned

\begin{tabular}{|c|c|c|c|c|c|}
\hline & CATEGORY & \multicolumn{3}{|c|}{ NO OF CASES } & PERCENTAGE (\%) \\
\hline \multirow{3}{*}{ GENDER } & MALES & \multicolumn{3}{|c|}{394} & 57.3 \\
\hline & FEMALES & \multicolumn{3}{|c|}{293} & 42.7 \\
\hline & AGE INTERVAL & $\mathbf{M}$ & $\mathbf{F}$ & TOTAL & \\
\hline \multirow{10}{*}{$\begin{array}{c}\text { AGE } \\
\text { (YEARS) }\end{array}$} & $0-9$ yrs & 14 & 11 & 25 & 3.6 \\
\hline & 10-19 yrs & 47 & 60 & 107 & 15.5 \\
\hline & 20-29 yrs & 44 & 67 & 111 & 16.1 \\
\hline & 30-39 yrs & 51 & 56 & 107 & 15.5 \\
\hline & 40-49 yrs & 65 & 43 & 108 & 15.7 \\
\hline & $50-59$ yrs & 73 & 29 & 102 & 14.8 \\
\hline & $60-69$ yrs & 63 & 17 & 80 & 11.6 \\
\hline & 70-79 yrs & 32 & 7 & 39 & 5.6 \\
\hline & $80-89$ yrs & 5 & 2 & 7 & 1 \\
\hline & 90-99 yrs & 1 & $\mathbf{0}$ & 1 & 0.1 \\
\hline
\end{tabular}

III). Maximum number of benign lesions was in the age group of 10-39 years constituting $63.3 \%$ followed by $25.4 \%$ cases in the age group $40-59$ years. Among the inflammatory cases maximum were seen in age group 20-29 years constituting $24.13 \%$. Malignancies were noted to be higher in the fifth decade comprising of almost about $66 \%$ of the total malignant cases in the age group 40-69 years. No malignancy was noted in the pediatric age group in our study (Table IV and Fig.1).

Benign lesions affected the organs in decreasing frequency as follows: oral cavity (19.1\%), thyroid (16.5\%), face $(16.5 \%)$, lesions over external nose \& paranasal sinus $(13.8 \%)$, otologic $(6.7 \%)$, salivary glands $(4.8 \%)$. The most common lesions in skin and soft tissues were epidermoid cysts followed by hemangiomas and lipomas. Squamous papillomas were found to be maximum among benign lesions of oral cavity. Goitre constituted the highest number of benign lesions in thyroid gland with predominance in females. Pleomorphic adenoma was the commonest tumor among benign lesions of salivary glands.

Of all inflammatory lesions, maximum was found over external nose and paranasal sinus (35\%) followed by $27 \%$ in oral cavity, $9.28 \%$ in otologic cases and $5.7 \%$ each in salivary glands and face. Nasal polyps, tonsillitis and adenoiditis were common inflammatory lesions in aero-digestive tract. Tuberculous lymphadenitis, granulomatous lymphadenitis and reactive lymphadenitis showed highest frequency among inflammatory lesions of lymph nodes. Malignant lesions were found maximum in oral cavity $(57.4 \%)$, followed by larynx (18.4\%) and 5.3\% in soft tissues of neck. 4\% malignant lesions were seen thyroid gland and $0.8 \%$ in salivary glands. Squamous cell carcinoma comprised the maximum number of malignant cases $(88 \%)$ and were seen most commonly in oral cavity followed by larynx (supraglottis). 
Table II: Distribution of lesions according to topography and histological type

\begin{tabular}{|c|c|c|c|c|c|c|c|c|c|c|}
\hline $\begin{array}{c}\text { SITE OF } \\
\text { LESION }\end{array}$ & \multicolumn{2}{|c|}{ BENIGN } & \multicolumn{2}{|c|}{ MALIGNANT } & \multicolumn{2}{c|}{ CONGENITAL } & \multicolumn{2}{c|}{ INFLAMMATORY } & \multicolumn{2}{c|}{ TOTAL } \\
\hline & $\begin{array}{c}\text { NO OF } \\
\text { CASES }\end{array}$ & $\%$ & $\begin{array}{c}\text { NO OF } \\
\text { CASES }\end{array}$ & $\%$ & $\begin{array}{c}\text { NO OF } \\
\text { CASES }\end{array}$ & $\%$ & $\begin{array}{c}\text { NO OF } \\
\text { CASES }\end{array}$ & $\%$ & $\begin{array}{c}\text { NO OF } \\
\text { CASES }\end{array}$ & $\%$ \\
\hline $\begin{array}{c}\text { NECK SOFT } \\
\text { TISSUE }\end{array}$ & 11 & 4.1 & 12 & 5.3 & 14 & 60.8 & 7 & 4 & 44 & 6.4 \\
\hline $\begin{array}{c}\text { NECK LYMPH } \\
\text { NODES }\end{array}$ & 5 & 1.8 & 1 & 0.4 & 2 & 8.6 & 3 & 1.7 & 11 & 1.6 \\
\hline $\begin{array}{c}\text { SALIVARY } \\
\text { GLANDS }\end{array}$ & 13 & 4.8 & 2 & 0.8 & 0 & 0 & 10 & 5.7 & 25 & 3.6 \\
\hline ORAL CAVITY & 51 & 19.1 & 128 & 57.4 & 3 & 13 & 47 & 27 & 229 & 33.3 \\
\hline FACE & 44 & 16.5 & 10 & 4.4 & 0 & 0 & 10 & 5.7 & 64 & 9.3 \\
\hline EAR & 18 & 6.7 & 6 & 2.7 & 4 & 17.4 & 16 & 9.2 & 44 & 6.4 \\
\hline NOSE \& PNS & 37 & 13.8 & 5 & 2.2 & 0 & 0 & 61 & 35 & 103 & 15 \\
\hline NASOPHARYNX & 2 & 0.7 & 7 & 3.1 & 0 & 0 & 2 & 1.1 & 11 & 1.6 \\
\hline SCALP & 26 & 9.7 & 0 & 0 & 0 & 0 & 3 & 1.7 & 29 & 4.2 \\
\hline THYROID & 44 & 16.4 & 9 & 4 & 0 & 0 & 8 & 4.6 & 61 & 8.8 \\
\hline $\begin{array}{c}\text { PARA } \\
\text { THYROID }\end{array}$ & 1 & 0.3 & 0 & 0.4 & 0 & 0 & 0 & 0 & 1 & 0.1 \\
\hline LARYNX & 10 & 3.7 & 41 & 18.3 & 0 & 0 & 5 & 2.8 & 55 & 8 \\
\hline EYE & 5 & 1.8 & 2 & 0.8 & 0 & 0 & 3 & 1.7 & 10 & 1.4 \\
\hline TOTAL & 267 & 38.8 & 223 & 32.5 & 23 & 3.3 & 174 & 25.32 & 687 & \\
\hline
\end{tabular}

\section{Discussion}

Lesions arising from head and neck region are both diversified and challenging with each disease having its own distinct epidemiologic anatomic and pathologic features, natural history and treatment considerations. The whole spectrum of head and neck lesions include a variety of differential diagnosis ranging from inflammatory to neoplastic. ${ }^{8}$

Overall, $57.5 \%$ of global head and neck cancers occur in Asia especially in India. Head and neck cancers in India accounted for $30 \%$ of all cancers. In India, 60 to $80 \%$ of patients present with advanced disease as compared to $40 \%$ in developed countries. The problem of managing head and neck cancers in India is somewhat different, as compared to the west. The major shortcoming is to cope up, with the loss to follow-up, which makes the task of conducting and reporting the end results of clinical trials awfully difficult. ${ }^{10}$ Over 200,000 cases of head and neck cancers occur each year in India. Nearly 80,000 oral cancers are diagnosed every year in our country. ${ }^{11}$ Nearly two-thirds of oral cancers are located in the buccogingival sulcus, where the betel quid is kept for long periods in the oral cavity. The location and etiology of this buccogingival cancer may warrant the term 'the Indian oral cancer'. ${ }^{10}$ 
Table III: Sex-wise distribution of lesions

\begin{tabular}{|c|c|c|c|}
\hline TYPE OF LESION & MALES & FEMALES & TOTAL \\
\hline BENIGN & 115 & 152 & 267 \\
\hline MALIGNANT & 186 & 37 & 223 \\
\hline CONGENITAL & 12 & 11 & 23 \\
\hline INFLAMMATORY & 81 & 93 & 174 \\
\hline TOTAL & 394 & 293 & 687 \\
\hline
\end{tabular}

Table IV: Age-wise distribution of lesions

\begin{tabular}{|c|c|c|c|c|c|}
\hline AGE INTERVAL & BENIGN & MALIGNANT & CONGENITAL & INFLAMMATORY & $\begin{array}{l}\text { TOTAL } \\
\text { CASES }\end{array}$ \\
\hline 0-9 yrs & 10 & $\mathbf{0}$ & 6 & 9 & 25 \\
\hline 10-19 yrs & 59 & 3 & 4 & 41 & 107 \\
\hline 20-29 yrs & 57 & 10 & 2 & 42 & 111 \\
\hline 30-39 yrs & 53 & 25 & 8 & 21 & 107 \\
\hline $40-49$ yrs & 33 & 49 & 1 & 25 & 108 \\
\hline 50-59 yrs & 35 & 49 & 0 & 18 & 102 \\
\hline 60-69 yrs & 15 & 51 & 2 & 12 & 80 \\
\hline 70-79 yrs & 4 & 29 & $\mathbf{0}$ & 6 & 39 \\
\hline 80-89 yrs & 1 & 6 & $\mathbf{0}$ & $\mathbf{0}$ & 7 \\
\hline $90-99$ yrs & $\mathbf{0}$ & 1 & $\mathbf{0}$ & $\mathbf{0}$ & 1 \\
\hline
\end{tabular}

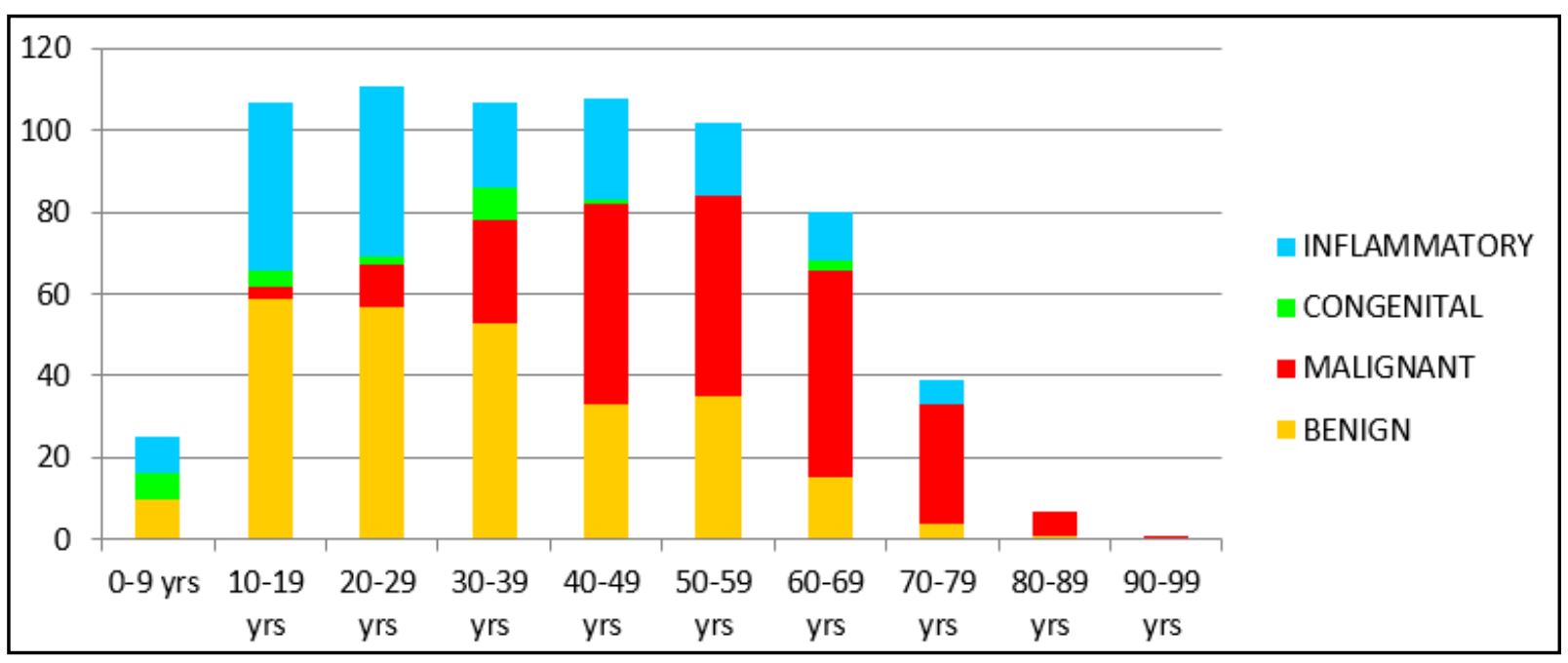

Fig. 1. Graphical representation of age wise distribution of lesions quite nicely depicts the increase in malignancy with increase in age, while the benign section comes down with age 
The head and neck lesions are routinely encountered across all ages. In our study, the age ranged from 3 years to 96 years. The maximum number of cases was present in the age range of 20 to 59 years contributing to $62.3 \%$, with the highest percentage being between 20 to 29 years. Least number of cases were seen in age 80 years and above $(0.8 \%)$. In a study by Lei et al, most lesions were distributed in a slightly higher age range of 50 to 59 years, followed by 40 to 49 years, and 30 to 39 years, all of which together comprised of $70.0 \%$ of all head and neck lesions. ${ }^{12}$ In another study conducted by Urooj et al, the age ranged between 1.5 to 80 years, whose result was similar to our present study. In their study, the most affected age group was $<30$ years $(41.40 \%)$ and least number of cases were reported in age group of 61 years and above, which was almost similar to the observation made by us. ${ }^{13}$

Kanu et al in their study, noted head and neck lesions to be present in ages ranging from 2 to 76 years which was lesser as compared to our study. ${ }^{3}$ The variations observed in the age range between our study and other studies can be attributed to demographic differences of the regions.

In the present study, the number of male patients was higher $(57.3 \%)$ as compared to female patients $(42.3 \%)$ with a male to female ratio of $1.34: 1$. Similar observation was noted in the study done by Urooj et al who reported $54 \%$ male and $46 \%$ female patients. ${ }^{13}$ Kanu et al also in their study reported a higher number of male cases $(54.6 \%)$ than female cases $(45.4 \%)$ with a male to female ratio of 1.2:1.3 Similarly, Ravi et al reported male predominance in their study with male: female ratio of 1.43:1.13 This was in concordance with our study. However, Lei et al, in their research, noted a male to female ratio of 3.4:1, which was much higher than what was observed in our data analysis. ${ }^{12}$ This could probably be because of a very large sample size of their study as compared to ours and because of different demographics of our regions.

In the current study, the topographic distribution of head and neck lesions was categorized into thirteen main sites which in the decreasing order of frequency of involvement were oral cavity, external nose and paranasal face, thyroid, neck soft tissues, otologic, scalp, salivary glands, nasopharynx, neck lymph nodes, ophthalmologic, parathyroid. Histopathologically, the lesions were further broadly grouped into benign, inflammatory and malignant accounting for $38.8 \%$, $25.32 \%$ and $32.46 \%$ respectively. Few premalignant or potentially malignant lesions like oral leukoplakia and submucosal fibrosis found were in our study.

In a study by Kanu et al, more number of benign cases $(63.3 \%)$ were reported which was compatible with our study. ${ }^{3}$ However, least number of benign lesions were noted in the study by Lei et al. ${ }^{12}$ The benign lesions were more frequent in the age group of 20 to 50 years while higher percentage of malignant lesions belonged to age group of 51 years and above in our research work. These observations were in agreement with the findings of Popat et al. ${ }^{5}$ Inflammatory lesions were maximum in the younger age of 20 years and below in our analysis. In pediatric age group, no malignant lesion was observed by us. Literature also shows that head and neck malignancies are uncommon in children and adolescents, constituting only $5 \%$ of all childhood malignant neoplasms. Supporting these findings was the retrospective study done by Al Yamani et al, who noted more benign lesions than malignant in their series. ${ }^{13}$ Similar observation was made by Popat et al. ${ }^{5}$ However, retrospective analysis of Lei et al, reported all categories of lesions to be more common in 50-59 years of age. ${ }^{12}$ Our research study showed a preponderance of males in the malignant segment whereas female had preponderance over inflammatory and benign categories.

Lei et al, however, reported fibromas as the commonest benign skin and soft tissue lesion followed by hemangiomas while epidermoid cyst was observed to be the most frequent entity among the non-odontogenic cystic lesions. ${ }^{12}$ Oral cavity lesions constituted 33.3\% of present study and were found to be more common in males. The most common site of involvement was lateral border of tongue followed by buccal mucosa and tonsils. Modi et al, however, reported an overall higher number of female patients with oral lesions than males. ${ }^{14}$

Benign lesions in the present study were squamous papilloma, pyogenic granulomas, epidermal cyst, lipoma as was also observed in other studies. Oral squamous cell carcinoma was the commonest malignancy reported in our work which was also seen in studies done by other authors. 
Inflammatory lesions included tonsillitis, adenoids and nasal polyps. Among the malignant lesions, squamous cell carcinoma was the most predominant malignancy. Five cases of nasopharyngeal carcinoma and four cases of non-Hodgkin's lymphoma were also reported. Popat et al also reported maximum number of squamous cell carcinomas in throat. ${ }^{5}$

In present study, the general topography indicated that oral cavity and larynx were most common sites affected by malignancy. Squamous cell carcinoma was the most frequently encountered malignancy in both these sites. These findings are indicative of the fact that head and neck cancers are amongst the commonest malignancies in India with squamous cell carcinoma being the predominant histological type. This could be attributed to the major preventable risk factors which are tobacco use, betel quid chewing and alcohol consumption. Placement of tobacco quid in the gingivobuccal sulcus region has been attributed to the development of carcinoma. Tongue and floor of mouth carcinoma are more common in western countries due to consumption of alcohol and smoking. Placement of tobacco quid in the gingivobuccal sulcus region has been attributed to the development of carcinoma.

Out of the $8.8 \%$ of the cases of the thyroid gland found in our study, non-neoplastic lesions were more common. Among these, most frequent entity was colloid goiter including both diffuse and nodular goiter, which were commonly seen in females. Similar findings were reported by Popat et al, Urooj et al and Rahman et al in their respective studies. ${ }^{5,13}$ Twelve cases of congenital thyroglossal cysts and eight cases of follicular adenoma was also noted in our study. Among the malignant lesions, three case of papillary carcinoma, one medullary carcinoma was reported.

Lymph node biopsy plays an important role in establishing the cause of lymphadenopathy. Among the biopsied lymph nodes, in present study, tuberculous lymphadenitis was the commonest lesion followed by reactive lymphadenopathy. Lymphomas were commonest cause for malignant lesions and included both Hodgkin's and non-Hodgkin's lymphoma. Metastases constituted the remaining nodal malignancies. Popat et al and Urooj et al also noted similar spectrum of lymph node lesions in their respective studies. ${ }^{5,13}$
Salivary glands constituted only $3.6 \%$ of all the head and neck lesions studied. Parotid Gland was the commonest site of lesion and women were more frequently affected than men in present series. Benign neoplastic lesions were common of which pleomorphic adenoma was the most frequent histological type. Malignant lesions included only adenocystic carcinoma. Inflammatory lesions included chronic sialadenitis. These finding are comparable with findings of Popat et al, Lei et al. ${ }^{5,12}$

The spectrum of head and neck lesions vary from region to region. Ours is a single centre based study which reflects specific patient population reporting to our hospital for ails and treatment. The overall general incidence and prevalence of the head and neck pathologies of this region reflects a lot about the population behavior, demography of this region.

\section{Conclusion}

The present study highlighted the whole spectrum of lesions ranging from benign to inflammatory to malignant and congenital, arising from head and neck region. The data regarding frequency, age, sex distribution of the cases along with the site and histological type of the lesion was evaluated in detail which helped in contributing to the baseline data of the head and neck lesions of the institute. The highest priority for cancer control should be given to the burden of head and neck cancer in India. With many head and neck cancers are difficult to manage, but being highly preventable, the emphasis, therefore, should be on preventing the onset and detecting the disease at an early stage. In developing countries like India, implementing cancer control activities has to be prioritized, making optimal use of limited resources to deliver the utmost benefit to the largest number of people.

\section{References}

1. Khetrapal S, Jetley S, Jairajpuri Z, Ratna S, Kohli S. FNAC of head and neck lesions and its utility in clinical diagnosis: A study of 290 cases. NJMR. 2015; 5:33-8

2. Suryawanshi KH, Damle RP, Dravid NV, Tayde Y. Spectrum of FNAC in palpable head and neck lesions in a tertiary care 
hospital in India-A 3 years study. IJPO. 2015; 2:7-13

3. Kanu OO, Nnnoli MA, Asoegwu CA. Prevalence of head and neck tumors in Calabar, South Eastern Nigeria. Asian J Med Sciences. 2016; 7:123-6

4. Lingen MW. Head and Neck. In: Kumar V, Abbas AK, Aster JC eds. Robbins and Cotran Pathologic Basis of Disease: Elsevier India. 2014; 727-48

5. Popat V, Vora D, Shah H. Clinico-pathological correlation of neck lesions- A study of 103 cases. Internet J Head Neck Surgery. 2009; 4(2)

6. Amit MU, Patel HL, Parmar BH. Study of cytodiagnosis of head and neck neoplastic lesions and comparison with histopathology. Int J Head Neck Surg. 2013; 4:119-22

7. Adisa AO, Adeyemi BF, Oluwasola AO, Kolude B. Clinicopathological profile of head and neck malignancies at University College Hospital, Ibadan, Nigeria. Head Face Med. 2011; 7:9

8. Sharma M, Sharma A, Gandhi S, Khajuria A, Goswami K.C. Histopathological patterns of head and neck lesions - a two year retrospective hospital based study. International Journal of Research in Medical Sciences Sharma M et al. Int J Res Med Sci. 2017 Apr; 5(4):1282-7
9. Alvarenga L, Torreglosa Ruiz M, Cristina E, Bertelli P, José M ,Ruback C, Maniglia J, Goloni-Bertollo E. Epidemiologic evaluation of head and neck patients in a university hospital of Northwestern São Paulo State

10. Kulkarni M. Head and Neck Cancer Burden in India. 10.5005/ jp-journals-10001-1132

11. Vigneswaran N, Williams M. Epidemiological Trends in Head and Neck Cancer and aids in diagnosis. Oral Maxillofac Surg Clin North Am. 2014 May;26(2): 123-41. j.c oms.2014.01.001

12. Lei F, Chen PH, Chen JY, Wang WC, Lin LM, Huang HC. Retrospective study of biopsied head and neck lesions in a cohort of referral Taiwanese patients. Head \& Face Medicine. 2014; $10: 28$

13. Urooj A, Mirza T, Ali A, Agha MA, Rasool S. Frequency of head and neck lesions according to histopathologic diagnosis. J Dow Univ Health Sciences Karachi. 2011; 5:70-3

14. Modi D, Laishram RS, Sharma LD, Debnath K. Pattern of oral cavity lesions in a tertiary care hospital in Manipur, India. J Med Soc. 2013; 27:199-202

15. Rahman MA, Biswas MA, Siddika ST, Sikder AM, Talukder SI, Alamgir MH. Histomorpholgical pattern of thyroid lesions. Dinajpur Med Col J. 2013; 6:134-40. 